of iron. In it he devoted special attention to the modification of the magnetic properties and of the chemical properties in relation to the resistance of iron to the action of chemical reagents. He gave examples showing that in cases where the silicon added to the iron attains a sufficiently high percentage the magnetic properties diminish, and the resistance to the action of acids increases with the proportion of silicon.

During the meeting visits were paid in the afternoons to the various iron works in the district and to the new graving-dock works on the river Tees. The social functions included a conversazione in the Town Hall, a ball given by the reception committee, a garden-party given by Lady Bell, a special performance at the Grand Opera House, luncheons in the Town Hall, and a luncheon given by the Tees Conservancy Commissioners at the Fifth Buoy Lighthouse.

\section{FISHING AND SEA-FOOD SUPPLIES OF THE} ANCIENT MAORI.

$\mathrm{I}^{\mathrm{N}}$ the second Bulletin of the Dominion Museum of New Zealand, the director, Mr. A. Hamilton, contributes an elaborate monograph on the fishing and sea-food supplies of the ancient Maori, based upon the investigation of numerous coastal kitchen-middens and camp sites. The importance of these sources of food supply is clearly illustrated by the Maori mythology, which abounds in tales of sea adventure and monsters of the deep. Among the mammalia, the only class affording food or valuable spoil, except the native rat and the imported dog, was the marine fauna, including the fur-seal, sea-leopard (Ogmorhinus leptonyx), and the sea-lion (Macrorhinus leoninus), of all of which traces are found in the middens in the form of bones and ornaments made from their teeth. One of the most valued prizes was the great sperm-whale (Physeter macrocephalus); but other members of the same group, such as the black-fish (Globiocephalus melas), were used for food. Of mollusca the consumption must have been enormous, one of the many middens consisting of shells of the Maori pipi (Mesodesma novae-zealandiae) being 340 feet long and more than 4 feet high. Many of these shells, particularly that of the beautiful Holiotus iris, were used in the preparation of ornaments. Among the crustaceans, the most valued were the red crayfish, crabs,

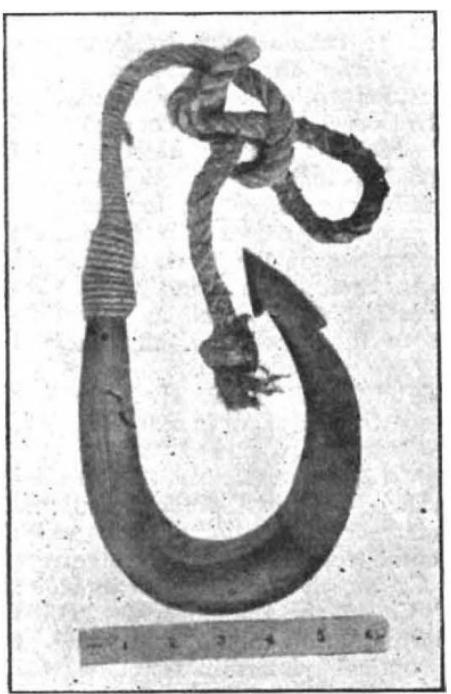

Fıg. I.-Large Wooden Hook for Shark. and shrimps. Seaurchins and many kinds of seaweed were collected from the rocks.

The variety of fish-hooks in greenstone, bone, or steatite is astonishing. Some objects of similar form seem to have been used as amulets, over which charms were recited to bring luck to the owner when he went fishing. This explanation accounts for some curious conventionalised examples, the use of which is otherwise not apparent. Like these are the remarkable greenstone pendants in the shape of an eel, which seem to have been employed for a similar purpose. The luck of the fishing community was also embodied in certain stones. When one of these was stolen, so recently as 1894 , the natives attributed an unsuccessful season to its loss.

In the sandhills many tools have been recovered which were used in preparing bone fish-hooks. The material was NO. 2032 , VOL. 78 ] worked into shape by the use of a drill moved by the alternate pulling of strings attached to the top of the spindle, the end of the drill being armed with a point of flint or quartz. When the hook was roughly shaped it was finished with rude sandstone files. The smaller hooks are usually formed of a single piece of bone, only one remarkable specirsen of a small composite hook having been recorded, though large examples are common. Sharks were captured in a net or with an immense wooden hook, young roots or branches being sometimes artificially bent while growing for this purpose. Still ruder are the double-pointed pieces of albatross bone, round which the bait being wrapped they were used as "gorges "-one of the most elementary of fishing implements, common in the European lake divellings. When the explorer and whaler came upon the scene these bone and stone hooks were quickly replaced by those of iron or copper; but the ancient forms were reproduced in the new materials. A

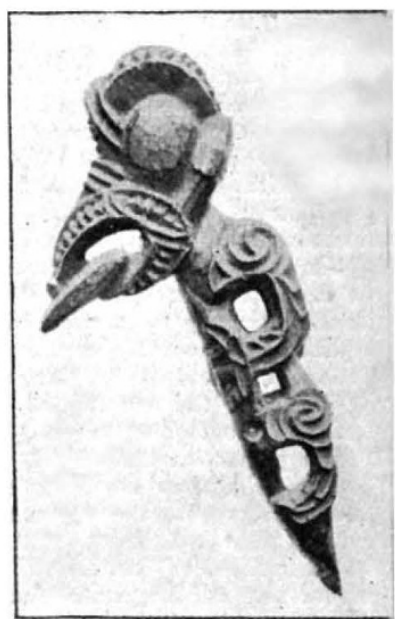

FiG. 2.-Figure carved on a fishing-rod. curious appendage to a fishing-rod is a carved figure to the lower part of which a number of valves of shell were attached. These rattle when a fish takes the bait and attract the attention of the fisherman. The net-sinkers form a large class. One specimen at Auckland, formerly described as a sea-god, seems to belong to this class, the sinker being worked into a semi-human shape and used to produce magical effects. The various kinds of modern fish-baskets and nets display considerable ingenuity and constructive skill.

Among the inland fish the ancient Maori depended chiefly upon the eel, which more than any other kind of food provided the much desired fat. For its capture they constructed huge works, only excelled in magnitude by their fortifications, in the shape of canals and weirs. They were well acquainted with the art of drying superfluous fish in huge earth ovens erected on the beach, and heated with a special kind of wood. When sufficiently cooked, the fish were taken out, as far as possible unbroken, placed on raised stages to dry, and finally packed in large fiax baskets for winter use.

Mr. Hamilton's monograph, which is well illustrated throughout, is an interesting contribution to the study of the commissariat and industries of primitive man.

\section{CHEMICAL DATA FOR THE GEOLOGIST.'}

GEOLOGY, as has sometimes been said, is less a distinct science than the meeting-ground of all the. sciences as applied to a distinct object, viz. as elucidating the history of the earth and its inhabitants. The working geologist therefore feels, more than most of his brethren, the necessity of gaining some acquaintance with numerous branches of knowledge in which he cannot pretend to be a specialist. In particular, the problems of physical geology and petrology are closely bound up with the modern developments of inorganic chemistry, and require not only a familiarity with general principles, but a knowledge of specific results, scattered through the pages of many journals and transactions of societies.

It is with results, rather than with principles, that the work before us is concerned; and the author has gathered into one volume a large body of information which is not to be found elsewhere in collected form. The work is necessarily that of a chemist rather than a geologist, but 1 " The Data of Geochemistry." By Frank Wigglesworth Clarke. Bull. No. 330 United States Geological Survey. Pp. $7 \pi 6$. (Washington, 1908.) 
Mr. Clarke's mineralogical researches and his connection with the laboratory of the United States Geological Survey well qualify him for a task of this kind.

The volume begins with a brief notice of the chemical elements, as regards their distribution and relative abundance in the known part of the globe, a subject to which the author has himself made some interesting contributions. Then follows a valuable summary, from the chemical point of view, of the nature of the atmosphere, the waters and saline contents of rivers, lakes, seas, and springs, and the gaseous constituents of igneous rocks, volcanic emanations, and fumeroles. A large number of analyses of air, waters, and gases are collated, and their bearing on some of the questions of physical geology indicated, with an occasional discursus upon such subjects as the composition of the primitive atmosphere and the source of volcanic water and gases.

This occupies one-third of the volume. About halr as much space is devoted to igneous rocks and their constituents. In this department any trustworthy data, beyond chemical analyses, are at present very scanty. The admirable work of Day and others at Washington, while providing us with accurate thermal constants for a few of the rock-forming minerals, has at the same time discredited practically all previous results in the same line. It appears, for instance, that the melting-point of anorthite, one of the most easily crystallised minerals, has been underestimated to the extent of $400^{\circ}$. The account here given of the several rock-forming minerals is accordingly little more than what is to be found in any text-book, excepting that the information concerning artificial reproduction of the minerals is brought down to date. The space might have been more profitably filled by a section written on the lines of the "Synthèse des Minéraux et des Roches" of Fouqué and Michel-Lévy. The fifty pages dealing with igneous rocks, under a peculiar scheme of classification, might well have been omitted. No useful purpose is served by selected analyses of rocks in a work of this kind, when complete collections of analyses are easily accessible.

The remaining chapters treat of the decomposition of rocks, sedimentary and detrital rocks, metamorphic rocks, metallic ores, the natural hydrocarbons, and coal. Under the last two heads especially there is a large amount of information which we have not seen elsewhere brought together in so complete a form.

The United States Geological Survey, taking a liberal view of its province, has from time to time issued publications dealing with general geological subjects, and among these the one now before us will take its place as a useful work of reference. It will be the more valued because the material is presented in a concise form, and the volume is of such size as to be easily handled without the aid of a lectern.

A. $\mathrm{H}$.

\section{THE INFLUENCE OF HUMIDITY ON RESISTANCES.}

MESSRS. ROSA AND BABCOCK, at the Bureau of Standards, found that manganin wire resistances used in resistance boxes varied according to the time of the year; for instance, in summer they were 0.015 per cent. to 0.025 per cent. higher in value than they were in the same temperature in winter. These experimenters explain this periodic variation by the fact that with increased relative air humidity the shellac, especially that between the metal tube and the wire, swells; the base on which the wire is wound consequently increases in diameter, and the forces thereby created cause the resistance wire to expand elastically. With decreasing humidity the shellac gives off moisture and shrinks, the pressure on the wire is relaxed, and the resistance decreases.

Tests just completed, and the results published (Zeitschrift für Instrumentenkunde, August), by the Reichsanstalt go to confirm this view, but the variations observed there are much slighter than those found at the Bureau of Standards. The tubes on which the wire is wound had hitherto been covered, first of all, with a sheet of silk, this being well covered with shellac; but in view of the humidity effect, tests were made with a number of specially prepared lacquers, but, so far as obtaining one which was impermeable to moisture was concerned, the experiments were futile. The author has therefore tried the effect of rendering the tubes to a certain degree elastic in order to combat the effect of the expansion mentioned, and has found that by providing them with longitudinal slots, and also dispensing with the preliminary covering of silk, a considerable advance has been made in this connection. In one coil mentioned in the results the six slots projected on both the upper and under sides to the extent of $3 \mathrm{~mm}$. bevond the windings, while in another tube the slots on the upper side projected I $\mathrm{cm}$. beyond the wire, reaching to the same distance as the wire on the under side. These coils were measured immediately after construction, and attained a constant value in a much shorter time than did the coils constructed hitherto.

With a view to obtain the maximum accuracr, the author also suggests that the resistance boxes should be continually filled with paraffin oil of a density of about o.86. Whether better results will really be obtained in this manner is at present the subject of experiment.

The test coils experimented on up to the present are, without exception, the long, thin form usual in resistance boxes. A few slots will not suffice for rendering more elastic the short, wide tubes used for standard resistances. It must remain for tests to ascertain what is the best form for these coils, and a research is already in hand with this obect.

The paper gives a full description of the experiments, and contains a number of curves showing the variations of a number of coils at the Reichsanstalt.

\section{THE OPENING OF THE MEDICAL SESSION.}

THE medical year of the schools of medicine in London and the provinces may be said to commence on or about October 1, and the opening of the session is in many instances made the occasion for the distribution of prizes, the delivery of addresses of welcome and advice, and the re-union of old friends at the "old students" dinners.',

At University College, after the distribution of medals and prizes by the Dean, Dr. Batty Shaw, Sir.Edward Fry addressed the students and their friends. $\mathrm{He}$ first offered his congratulations on the admirable buildings in which the work of the school is now carried on, and then made some remarks on the professional ideal. The advantage of a profession over a trade is that it sets a higher ideal before a man; it requires of him to benefit the persons for whom he acts without regard to any private interest of his own. The legitimate gain which must accrue will be a secondary object rather than a primary one. It is on this ground that, quite justly, the world expects of professional men a higher standard of intelligence and of morals than it requires of the mere tradesman. Every true student should be a student all his life through; he should be able to say with old Solon, "I grow old always learning many things." Finally, Sir Edward touched on the relation of the medical profession and the State, pointing out that it is obvious that the medical profession is becoming more and more occupied with public business, and that its aid is being more and more invoked by the governing authorities. He referred to the investigations that are being made by the direction of the Privy Council, the various commissions that are being issued dealing with tuberculosis and other aspects of disease, the scheme now being put into practice for the medical examination of scholars in the primary schools, and the appointment of medical officers of health throughout the country. The medical profession is being drawn in an increasing degree closer to the work and objects of the State. However close that relationship may become in the future, it is hoped that the medical profession will strive to maintain its independence, and will never believe that it is to be subservient to the State.

At King's College Dr. Alexander MacAlister delivered an address on fifty years of medical education. After

NO. 2032, VOL. 78] 